\title{
Determining optimal kinematic parameters of a screen shoe used for separating breeding seed samples
}

\author{
Maksim Moskovskiy ${ }^{1, *}$, Victor Khamuev ${ }^{1}$, Aleksei Dorokhov ${ }^{1}$, and Stanislav Gerasimenko ${ }^{1}$ \\ ${ }^{1}$ Federal Scientific Agro-Engineering Center VIM, 1 Institutsky proezd, 5, Moscow, 109428, Russia
}

\begin{abstract}
In the post-harvest processing of breeding material, the absence of a sieve machine of appropriate productivity that meets all the requirements for breeding machines is relevant today. For research, a mock stand of the sieve machine was used, on which the kinematic parameters of the sieve mill and the tilt angles of the sieves were determined.
\end{abstract}

\section{Introduction}

To perform cleaning and sorting of seed samples grown on breeding plots, usy is made of complex machines from domestic and foreign producers [1-3]. Domestic machines feature the performance rate less than $150 \ldots .200 \mathrm{~kg} / \mathrm{h}$. Processing lots of seeds weighing more than $15 \mathrm{~kg}$ with these machines is economically unfeasible. In this respect, there is a need to have a set of simple machines: an aspiration column, a screen cleaner and a grain sifter, which could be used depending on the content of impurities in the source material, either independently or as a production line. The most vivid drawback in post-harvest processing of breeding material today is the lack of a screen cleaner of an appropriate performance that could meet all the requirements for breeding machines [4-7].

The research purpose - to develop a screen cleaner for breeding enterprises and determine the kinematic parameters of its screen shoe, to study the influence of the inclination angle of the screen shoe on the performance.

\section{Material and methods}

The authors considered materials of theoretical and experimental studies on the cleaning of breeding seeds. For the experiments, use was made of a model bench of a screen cleaner shown in Fig. 1.

Kinematic parameters of the screen shoe. As the source material for the experiments, use was made of wheat with a seed variety purity of $97.9 \%$, pre-treated in a vertical air

\footnotetext{
* Corresponding author: maxmoskovsky74@yandex.ru
} 
flow, after which all the light impurities were removed. The grain material contained $1.76 \%$ of fine and $0.34 \%$ of large impurities.
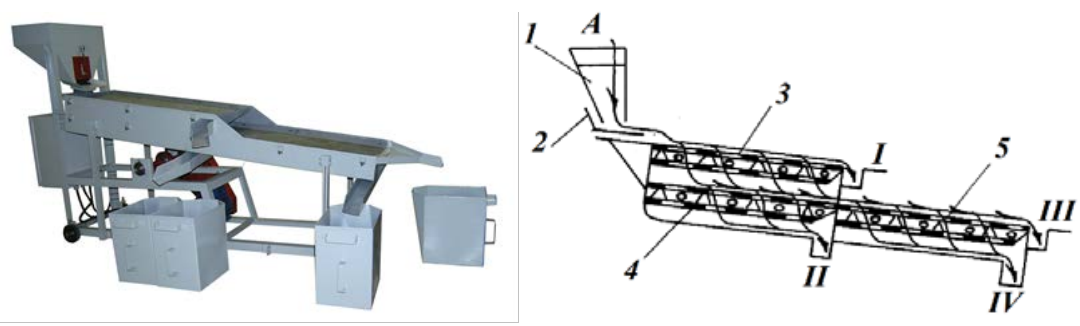

Fig. 1. Model bench of a seed cleaner: 1 - loading hopper; 2 - vibratory feeder; 3 - primary screen; 4 - cleaning screen; 5 - separating screen; I - large impurities; II - fine impurities (dunst); III - cleaned material; IV - second grade.

The screen cleaner bench included: an upper screen with round holes of $\varnothing 4.5 \mathrm{~mm}$ in diameter and a lower screen with oblong holes of $\emptyset 2.0 \mathrm{~mm}$. The screens were of the same size $-790 \times 400 \mathrm{~mm}$. The upper screen featured a slightly smaller size of the holes for the purpose of a more visual and a precise study of the effect of loading and kinematic parameters of the screen shoe on the quality of grain material separation.

The material was divided into three fractions at a capacity of $500 \pm 5 \mathrm{~kg} / \mathrm{h}$ : the siftings from the upper screen, the siftings from the lower screen and the pass through the lower screen. All fractions were weighed on AND GF600 scales and analyzed. Upon the analysis results, the authors determined the extraction coefficient for small impurities using a formula

$$
K=\frac{Q_{i m}}{Q_{o}} \cdot 100 \%,
$$

where $\mathrm{Q}_{\mathrm{im}}$ is the amount of impurities passing from the lower screen, \%; $\mathrm{Q}_{\mathrm{o}}$ - the amount of fine impurities in the initial material, \%.

The authors determined the losses of seeds in the total amount of material siftings from the upper screen, and the weight of 1000 seeds in the outcomes of the upper and lower screens.

The clogging of screens was determined after passing through them an amount of seeds weighing $10 \mathrm{~kg}$. After the processed material passed through the machine, the latter continued to work idle for another minute. Then the screens were removed, turned over $180^{\circ}$ upside down, to let off all the unseized grain seeds. Further on, the seized grains were separately removed from the holes of the upper and lower screens, collected, and weighed with scales.

The clogging of screens was determined with a formula:

$$
K_{3}=\frac{m_{1}}{m} \cdot 100 \%
$$

where $\mathrm{m}_{1}$ is the mass of seeds seized in the holes, $\mathrm{g}$; $\mathrm{m}$ - the mass of seeds passing onto the screen, g.

One of the main parameters of grain separation mode are the number of vibrations per minute $\mathrm{n}$ and the amplitude A, which are called kinematic parameters. The acceleration of 
the screen determined with the expression $\omega^{2} \mathrm{~A}(\omega$ is the angular velocity of the eccentric, $\mathrm{rad} / \mathrm{s}$ ) is referred to as a kinematic indicator of the screen. The experiments were carried out at five vibration amplitude variants of the screen shoe (7, 10, 14, 18 and $22 \mathrm{~mm}$ ) when the vibration frequency changed from $169 \mathrm{~min}-1$ at $\mathrm{A}=22 \mathrm{~mm}$ to $470 \mathrm{~min}-1$ at $\mathrm{A}=7 \mathrm{~mm}$. The kinematic indicator of the screen ranged between 6.9 and $19.3 \mathrm{~m} / \mathrm{s} 2$.

The inclination angle of the screen shoe. The experiments were carried out on the same initial material at two inclination angles of the screen shoe of 6 and 90 . The influence of the screen shoe angle inclination on the machine performance and cleaning quality of wheat seeds was determined at a constant value of the kinematic indicator of the screen $\omega 2 \mathrm{~A}=$ $12.9 \mathrm{~m} / \mathrm{s} 2$. Only the area of the hopper's exhaust window changed in the range of 26.4...39.6 $\mathrm{cm}^{2}$.

\section{Results and discussion}

The experimental results on the determination of the kinematic parameters of a screen shoe are presented in Table. 1 and Figure. 2.

An increase in the kinematic indicator of the screens is accompanied by more intensive clogging of their holes. For example, at a change of this indicator from 6.9 to $19.3 \mathrm{~m} / \mathrm{s} 2$, clogging of a screen with oblong holes decreased from 0.34 to $0.02 \%$, and that of a screen with round holes, - respectively from 0.019 to $0 \%$. We should note that screens with round holes clogged about 10 times less frequently than those with oblong holes in all operation modes.

Table. 1. The rate of screen clogging in course of cleaning wheat seeds depending on the kinematic indicator value of the screen shoe.

\begin{tabular}{|c|c|c|c|c|c|c|c|}
\hline \multirow[b]{2}{*}{ № } & \multirow{2}{*}{$\begin{array}{l}\text { Kinematic } \\
\text { indicator of } \\
\text { the screen } \\
\text { shoe } \\
\omega^{2} \mathrm{~A}, \text { min- } 1\end{array}$} & \multicolumn{2}{|c|}{$\begin{array}{l}\text { Screen clogging, } \\
\%\end{array}$} & \multirow[b]{2}{*}{ № } & \multirow{2}{*}{$\begin{array}{l}\text { Kinematic } \\
\text { indicator of } \\
\text { the screen } \\
\text { shoe } \quad \omega^{2} \mathrm{~A}, \\
\text { min-1 }\end{array}$} & \multicolumn{2}{|c|}{$\begin{array}{l}\text { Screen clogging, } \\
\%\end{array}$} \\
\hline & & $\begin{array}{l}\text { upper } \\
\varnothing 4.5 \\
\text { mm }\end{array}$ & $\begin{array}{l}\text { lower } \\
\varnothing \quad 2.0 \\
\mathrm{~mm}\end{array}$ & & & $\begin{array}{l}\text { upper } \\
\varnothing 4.5 \\
\mathrm{~mm}\end{array}$ & $\begin{array}{l}\text { lower } \\
\varnothing 2.0 \\
\mathrm{~mm}\end{array}$ \\
\hline \multicolumn{4}{|c|}{$\mathrm{A}=7 \mathrm{~mm}$} & \multicolumn{4}{|c|}{$\mathrm{A}=18 \mathrm{~mm}$} \\
\hline 1 & 16.95 & 0.01 & 0.17 & 1 & 16.24 & 0 & 0.030 \\
\hline 2 & 14.85 & 0.01 & 0.15 & 2 & 13.5 & 0.003 & 0.047 \\
\hline 3 & 12.9 & 0.02 & 0.27 & 3 & 11.08 & 0.009 & 0.111 \\
\hline 4 & 11.08 & 0.02 & 0.46 & 4 & 9.98 & 0.010 & 0.090 \\
\hline 5 & 9.4 & 0.03 & 0.34 & 5 & 8.9 & 0.010 & 0.120 \\
\hline \multicolumn{4}{|c|}{$\mathrm{A}=10 \mathrm{~mm}$} & 6 & 6.9 & 0.02 & 0.170 \\
\hline 1 & 19.3 & 0 & 0.02 & \multicolumn{4}{|c|}{$\mathrm{A}=22 \mathrm{~mm}$} \\
\hline 2 & 17.5 & 0.002 & 0.038 & 1 & 16.3 & 0 & 0.020 \\
\hline 3 & 15.8 & 0,005 & 0.095 & 2 & 13.5 & 0.005 & 0.045 \\
\hline 4 & 14.2 & 0.006 & 0.144 & 3 & 11.00 & 0.004 & 0.086 \\
\hline 5 & 12.7 & 0.01 & 0.15 & 4 & 8.9 & 0.007 & 0.123 \\
\hline 6 & 11.2 & 0.016 & 0.164 & 5 & 6.9 & 0.014 & 0.216 \\
\hline 7 & 9.9 & 0.05 & 0.28 & & & & \\
\hline 8 & 8.6 & 0.03 & 0.29 & & & & \\
\hline \multicolumn{4}{|c|}{$\mathrm{A}=14 \mathrm{~mm}$} & & & & \\
\hline 1 & 15.9 & 0.002 & 0.018 & & & & \\
\hline 2 & 13.6 & 0.006 & 0.054 & & & & \\
\hline 3 & 11.1 & 0.008 & 0.112 & & & & \\
\hline 4 & 9.9 & 0.010 & 0.100 & & & & \\
\hline 5 & 8.83 & 0.018 & 0.141 & & & & \\
\hline 6 & 6.9 & 0.019 & 0.151 & & & & \\
\hline
\end{tabular}


The sifting performance of the screen with round holes was the best at kinematic parameters of screens equaling $11.0 \ldots 13.0 \mathrm{~m} / \mathrm{sec} 2$. Higher results were obtained at amplitudes of $7 \ldots 10 \mathrm{~mm}$ and screen vibration frequencies of 410 and $340 \mathrm{~min}-1$, respectively.

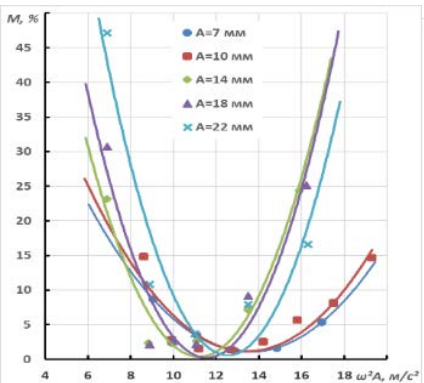

a

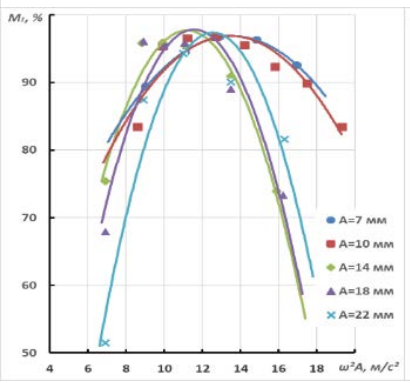

b

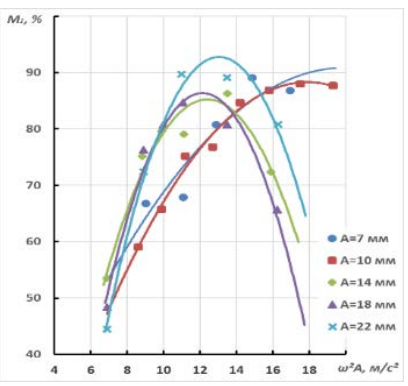

$\mathrm{C}$

Fig. 2. The amount passing from the upper screen (a), the amount passing from the lower screen (b) and the extraction coefficient of small impurities (c) depending on the value of the kinematic indicator of screens

Optimal values of the kinematic indicator of the screens with oblong holes, depending on the vibration amplitude, are within $11.0 \ldots 15.0 \mathrm{~m} / \mathrm{sec} 2$. The extraction coefficient of small impurities in this case ranges between 84.6 and $89.6 \%$. The lower the amplitude is, the greater value of the kinematic indicator of a screen should be observed. Thus, for an amplitude $\mathrm{A}$ of $7 \mathrm{~mm}$, the optimal value of the kinematic indicator of a screen $\omega^{2} \mathrm{~A}$ equals $14.85 \mathrm{~m} / \mathrm{sec} 2$, and at $A$ of $22 \mathrm{~mm}, \omega^{2} \mathrm{~A}$ is equal to $11.0 \mathrm{~m} / \mathrm{sec} 2$. It should be noted that for screens with oblong holes, optimal values of the kinematic indicator (except for data obtained at $\mathrm{A}=22 \mathrm{~mm}$ ) are more important than for screens with round holes. So, if at an amplitude $A$ of $7 \mathrm{~mm}$, the optimal value $\omega^{2} \mathrm{~A}$ for screens with oblong holes is $14.85 \mathrm{~m} / \mathrm{sec} 2$, and for screens with round holes $\omega^{2} \mathrm{~A}=12.9 \mathrm{~m} / \mathrm{sec} 2$, but at an amplitude $\mathrm{A}$ of $14 \mathrm{~mm}$, respectively, $\omega^{2} \mathrm{~A}=13.5 \mathrm{~m} / \mathrm{sec} 2$ for screens with round holes.

At larger values of the kinematic indicator of screens $(\omega 2 \mathrm{~A}>15.5 \mathrm{~m} / \mathrm{sec} 2)$, the grain mass is strongly loosened, the process of sifting sharply deteriorates, and the mass (up to 25.5\%) overtails from the upper screen.

At small values of the kinematic indicator $(\omega 2 \mathrm{~A}<8.0 \mathrm{~m} / \mathrm{sec} 2)$, the grain mass on the screen is not loosened, but it is poorly transported, and the quality of sifting sharply deteriorates.

The extraction coefficient of small impurities drops to $44.5 \%$, and the capacity of the screen shoe cannot be raised above $300 \ldots 325 \mathrm{~kg} / \mathrm{h}$, though in all experiments, the authors have tried to set the performance within $500 \pm 5 \% \mathrm{~kg} / \mathrm{h}$. At small values of the screen vibration amplitude ( $\mathrm{A}=3 \mathrm{~mm}$ ), the grain separation process is not working at all tested vibration frequencies of a screen (up to $450 \mathrm{~min}-1$ ).

On the basis of the conducted research it is possible to recommend the following kinematic modes for the separation of wheat seeds:

$$
\begin{aligned}
& \mathrm{A}=7 \mathrm{~mm}, \mathrm{n}=410 \ldots 440 \mathrm{~min}-1(\omega 2 \mathrm{~A}=12.9 \ldots 14.85 \mathrm{~m} / \mathrm{sec} 2) ; \\
& \mathrm{A}=10 \mathrm{~mm}, \mathrm{n}=350 \ldots 370 \mathrm{~min}-1(\omega 2 \mathrm{~A}=13.5 \ldots 15.0 \mathrm{~m} / \mathrm{sec} 2) ; \\
& \mathrm{A}=14 \mathrm{~mm}, \mathrm{n}=250 \ldots 280 \mathrm{~min}-1(\omega 2 \mathrm{~A}=9.9 \ldots 12.0 \mathrm{~m} / \mathrm{sec} 2) ; \\
& \mathrm{A}=18 \mathrm{~mm}, \mathrm{n}=225 \ldots 240 \mathrm{~min}-1(\omega 2 \mathrm{~A}=9.98 \ldots 11.1 \mathrm{~m} / \mathrm{sec} 2) ; \\
& \mathrm{A}=22 \mathrm{~mm}, \mathrm{n}=214 \ldots 220 \mathrm{~min}-1(\omega 2 \mathrm{~A}=11.0 \ldots 11.3 \mathrm{~m} / \mathrm{sec} 2)
\end{aligned}
$$


that will be close to the optimal values for the performance of a screen shoe, equal to $500 \pm 5 \mathrm{~kg} / \mathrm{h}$, for both screens with round holes and those with oblong ones.

When installing screens with oblong holes only in the screen shoe, the following operating modes can be recommended:

$$
\begin{aligned}
& \mathrm{A}=7 \mathrm{~mm}, \mathrm{n}=440 \mathrm{~min}-1(\omega 2 \mathrm{~A}=14.85 \mathrm{~m} / \mathrm{sec} 2) \\
& \mathrm{A}=10 \mathrm{~mm}, \mathrm{n}=360 \mathrm{~min}-1(\omega 2 \mathrm{~A}=14.2 \mathrm{~m} / \mathrm{sec} 2) ; \\
& \mathrm{A}=14 \mathrm{~mm}, \mathrm{n}=300 \mathrm{~min}-1(\omega 2 \mathrm{~A}=13.5 \mathrm{~m} / \mathrm{sec} 2) ; \\
& \mathrm{A}=18 \mathrm{~mm}, \mathrm{n}=240 \mathrm{~min}-1(\omega 2 \mathrm{~A}=11.1 \mathrm{~m} / \mathrm{sec} 2) \\
& \mathrm{A}=22 \mathrm{~mm}, \mathrm{n}=214 \mathrm{~min}-1(\omega 2 \mathrm{~A}=11.0 \mathrm{~m} / \mathrm{sec} 2)
\end{aligned}
$$

In these modes, the separation efficiency of small impurities is equal to $84.6 . . .89 .6 \%$ and clogging of screens does not exceed $0.15 \%$. When installing screens with round holes only in a screen shoe, the following operating modes can be recommended:

$$
\begin{aligned}
& \mathrm{A}=7 \mathrm{~mm}, \mathrm{n}=410 \mathrm{~min}-1(\omega 2 \mathrm{~A}=12.9 \mathrm{~m} / \mathrm{sec} 2) ; \\
& \mathrm{A}=10 \mathrm{~mm}, \mathrm{n}=340 \mathrm{~min}-1(\omega 2 \mathrm{~A}=12.7 \mathrm{~m} / \mathrm{sec} 2) ; \\
& \mathrm{A}=14 \mathrm{~mm}, \mathrm{n}=254 \mathrm{~m} \mathrm{~min}-1(\omega 2 \mathrm{~A}=9.9 \mathrm{~m} / \mathrm{sec} 2) ; \\
& \mathrm{A}=18 \mathrm{~mm}, \mathrm{n}=212 \mathrm{~min}-1(\omega 2 \mathrm{~A}=8.9 \mathrm{~m} / \mathrm{sec} 2) ; \\
& \mathrm{A}=22 \mathrm{~mm}, \mathrm{n}=214 \mathrm{~min}-1(\omega 2 \mathrm{~A}=11.0 \mathrm{~m} / \mathrm{sec} 2)
\end{aligned}
$$

\begin{tabular}{|c|c|c|c|c|}
\hline \multirow[b]{2}{*}{ № } & \multirow{2}{*}{$\begin{array}{l}\text { The area of the } \\
\text { hopper outlet } \\
\text { window, cm2 }\end{array}$} & \multirow{2}{*}{$\begin{array}{l}\text { The } \\
\text { inclination } \\
\text { angle of the } \\
\text { screens, }\end{array}$} & \multicolumn{2}{|c|}{ Screen clogging, \% } \\
\hline & & & $\begin{array}{l}\text { upper } \\
\varnothing 4.5 \mathrm{~mm}\end{array}$ & $\begin{array}{l}\text { lower } \\
\varnothing 2.0 \mathrm{~mm}\end{array}$ \\
\hline \multirow{2}{*}{1} & \multirow{2}{*}{26.4} & 6 & 0.004 & 0.16 \\
\hline & & 9 & 0.026 & 0.38 \\
\hline \multirow{2}{*}{2} & \multirow{2}{*}{29.7} & 6 & 0.003 & 0.18 \\
\hline & & 9 & 0.018 & 0.32 \\
\hline \multirow{2}{*}{3} & \multirow{2}{*}{33.0} & 6 & 0.002 & 0.18 \\
\hline & & 9 & 0.021 & 0.33 \\
\hline \multirow{2}{*}{4} & \multirow{2}{*}{36.3} & 6 & 0.002 & 0.15 \\
\hline & & 9 & 0.019 & 0.35 \\
\hline \multirow{2}{*}{5} & \multirow{2}{*}{39.6} & 6 & 0.006 & 0.17 \\
\hline & & 9 & 0.018 & 0.36 \\
\hline
\end{tabular}

These modes will ensure maximum sifting and clogging of the screens will not exceed $0.02 \%$. The experimental results to determine the inclination angle of a screen shoe are shown in Tab. 2 and Fig. 3. At an increase in the hopper outlet window area, the machine performance grows as well at all inclination angles of the screens. And with higher inclination angles, the performance was greater by about $40 \mathrm{~kg} / \mathrm{h}$ at all operating modes.

Table. 2. The rate of screen clogging during the cleaning of wheat seeds, depending on the inclination angle of the screens $(\omega 2 \mathrm{~A}=12.9 \mathrm{~m} / \mathrm{sec} 2)$ 

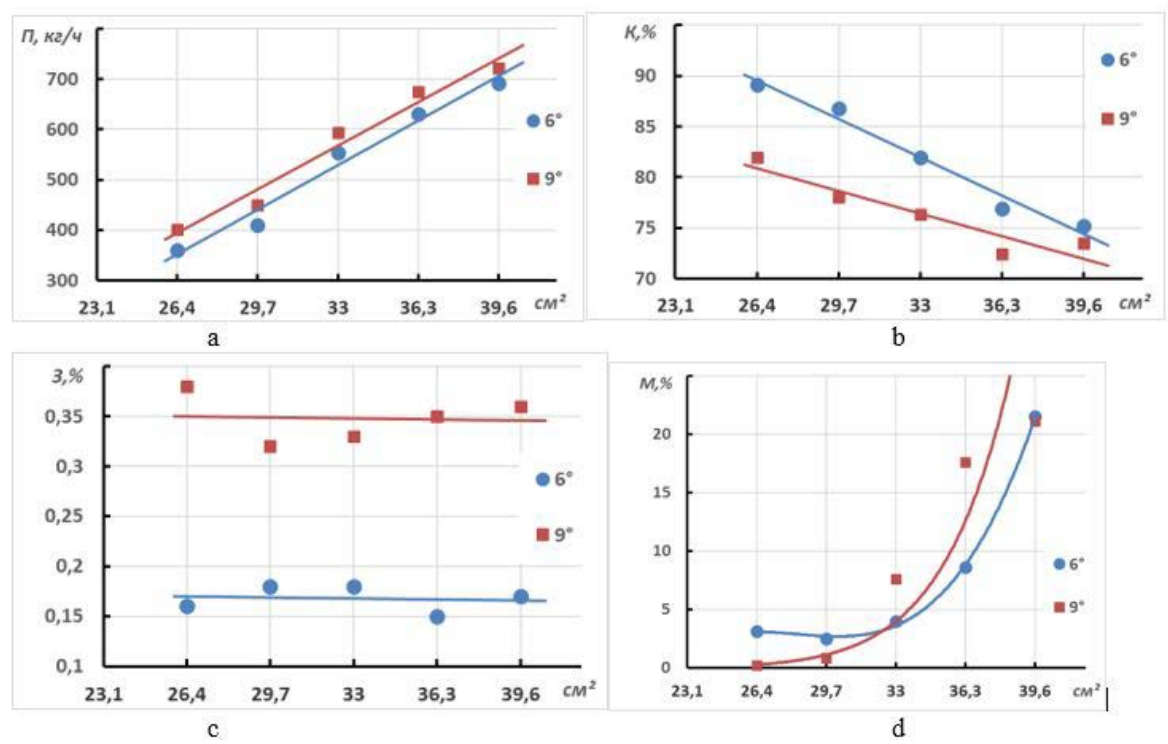

Fig. 3. The performance of the screen shoe in cleaning of wheat seeds, depending on its inclination angle:

$\mathrm{a}$ - change in the shoe performance; $\mathrm{b}$ - change in the extraction coefficient of small impurities;

$\mathrm{c}$ - change in lower screen clogging; $\mathrm{d}$ - change in the amount of siftings from the upper screen.

The coefficient of extraction of small impurities decreases as the performance grows by a dependence that is close to linear. So, at an inclination angle of the screen shoe $\chi=0^{\circ}$, the coefficient decreased from 89.12 to $75.2 \%$ at the performance rate, respectively equal to 360.1 and $691.9 \mathrm{~kg} /$. At an inclination angle $\chi=9^{\circ}$, the coefficient decreased from 81.91 to $73.51 \%$ with an increase in performance from 400.5 to $721.3 \mathrm{~kg} / \mathrm{h}$. It should be noted that at the performance rate above $600 \mathrm{~kg} / \mathrm{h}$, the values of the extraction coefficients of small impurities converge and range within $72.4 \ldots 76.86 \%$, i.e. the inclination angle of screens does not have almost any effect on this indicator. The clogging of the screens is almost the same for all performance values. At a large inclination angle of the screens $\left(\chi=9^{\circ}\right)$, the penetration rate of the upper screen (with round holes) is 3...10 times higher, and that of the lower screen (with rectangular holes) is about 2 times higher as compared with screen clogging at an inclination angle of $6^{\circ}$. The siftings from the upper screen at the performance rate of up to $450 \mathrm{~kg} / \mathrm{h}$ was less (up to $1 \%$ ) at an inclination angle of the screen shoe $\chi=9^{\circ}$, and the screen shoe performance rate of $593.2 \ldots 674.5 \mathrm{~kg} / \mathrm{h}$, it increased up to $7.6 \ldots 17.59 \%$ and became $2 . . .3$ times higher than the amount of siftings for the inclination angle of the screens of $6^{\circ}$. At $691.9 . . .721 .3 \mathrm{~kg} / \mathrm{h}$, the screen value remained the same.

The carried out research has allowed to determine the operating modes of a screen shoe, which are close to optimal for the separation of grain seeds. However, the developed screen seed cleaner should process the seed material of small-seed crops (grass, etc.), which is usually heavily clogged with various impurities. According to V. Lampeter, for their effective removal, the kinematic indicators of the screen should not be less than 14.4 $\mathrm{m} / \mathrm{sec} 2$ and the inclination angle of the screen shoe should equal $7^{\circ}$. 


\section{Conclusion}

In order for a screen seed cleaner to operate in modes that are close to optimal when processing small-seed and grain crops, the vibration amplitude of the screen shoe should be equal to $9 \mathrm{~mm}$, and its vibration frequency should be adjustable in the range of $350 . .450$ min-1 at an inclination angle of the screens of $7^{\circ}$. In this case, a screen seed cleaner can operate with an adjustable value of the kinematic indicator of screens in the range of $12.2 \ldots 20.0 \mathrm{~m} / \mathrm{sec} 2$, which will allow processing seed material of practically all crops with different content of impurities.

\section{References}

1. A.Yu. Izmaylov, N.Ye. Yevtyushenkov. Mechanization of breeding and experimental work. Mekhanizatsiya i elektrifikatsiya sel'skogo khozyaystva, 2016; 4: 4-9.

2. A.Yu. Izmaylov. VIM: 85 years in the forefront of the domestic agricultural machinery engineering. Sel'skokhozyaystvennyye mashiny i tekhnologii, 2014; 6: 10-13.

3. A.Yu. Izmaylov, Ya.P. Lobachevskiy. Development of machinery for breeding and seed production as one of the priorities of agricultural engineering. Sbornik statey: Sostoyaniye i razvitiye regional'nogo mashinostroyeniya. M.: FGNU Rosinformagrotekh, 2010: 96-103.

4. M.N. Moskovsky, Yu.A. Tsarev, A.A. Doroshenko. Evaluation of the performance of the sieve separators producing feed material (fodder) by barley cleaning. Trudy Kubanskogo gosudarstvennogo agrarnogo universiteta, 2010; 25: 161-164.

5. M.N. Moskovsky, A.A. Boyko. Comparative assessment of macrodamage to wheat grain observed with variable seed cleaning patterns in a grain cleaning unit. Inzhenernyy vestnik Dona, 2014; 1 (28): 44-49.

6. M.N. Moskovsky, Synthesis of system solutions of the technological process of obtaining seeds on the basis of structural and functional modeling: DSc (Eng) thesis: 05.20.01. Kubanskiy gosudarstvennyy agrarnyy universitet im. I.T. Trubilina. Rostovna-Donu, 2017. (in Rus.).

7. M.N. Moskovsky, M.M. Chaava, I.V. Chumak. Development of a structural-functional model of a single production process obtaining seed material in farms. ARPN Journal of Engineering and Applied Sciences, 2018; 13 (6): 2157-2165. 